\title{
STRUCTURAL PERFORMANCE FOR WIDE-SHALLOW BEAM IN SHEAR (COMPARATIVE STUDY)
}

\author{
By
}

\author{
Abd El-Hakim Khali1 ${ }^{1}$, Emad Etman ${ }^{1}$, Ahmed Atta ${ }^{1}$, A.T. Baraghith ${ }^{2}$ and R.N.Behiry ${ }^{3}$ \\ ${ }^{1}$ Professor, Structural Engineering Dept., Faculty of Engineering, Tanta University, Tanta, Egypt \\ ${ }^{2}$ Assistant Professor, Structural Engineering Dept., Faculty of Engineering, Tanta University, Tanta, Egypt \\ ${ }^{3}$ Assistant Lecturer, Structural Engineering Dept., Faculty of Engineering, Tanta University, Tanta, Egypt
}

\begin{abstract}
Many floor systems contain wide shallow beams to carry floor loads and transfer it to columns. For example, in bridge construction, a system of wide shallow beams (WSBs) may provide a simple and economical system to transfer loads from the slab deck to columns. In many of these design situations, it is often advantageous to use different member widths to minimize reinforcement conflicts and reduce overall congestion. This geometrical peculiarity deserves some attention and caution while dealing with the behaviour at ultimate limit states for shear and flexure. Seven wide-shallow beams with edge columns specimens were used to investigate the effect of width to depth ratios (b/d) and column width to beam width ratios $(\mathrm{c} / \mathrm{b})$ on the performance of shear capacity. The performances were measured in terms of deflection, ultimate loads, crack patterns, web reinforcement strains, and shear strain distribution a cross width. The results revealed that, the contribution of concrete formals of the international codes must be recalibrated.
\end{abstract}

\section{INTRODUCTION}

Many floor systems contain wide shallow beams to carry floor loads and transfer it to columns. For example, in bridge construction, a system of wide shallow beams may provide a simple and economical system to transfer loads from the slab deck to columns. In many of these design situations, it is often advantageous to use different member widths to minimize reinforcement conflicts and reduce overall congestion. Common practice is to use beams which are wider than the supporting columns as illustrated in Fig.1, the geometric differences in member width between beam and column will create a difference force flow in the beam compared with the beams that support on columns with the same width.

Recently, some researchers directed their efforts to study the shear behavior of wide shallow beams. Lubell et al., 2009 and Serna et al., 2002 investigated the influence of the stirrups cross spacing on the shear capacity of wide shallow RC beams. The study concluded that the effectiveness of stirrups increases as the spacing of web reinforcement legs across the width of decreases and also the mode of failure is more brittle when widely spaced up to a distance of approximately twice the effective depth. Sherwood et al., 2007carried out an experimental study to compare between the behavior of the wide shallow beams and thick slabs in shear. They tested five specimens of normal strength concrete with a nominal thickness of $470 \mathrm{~mm}$ and varied in width from 250 to $3005 \mathrm{~mm}$. The study ended to that the failure shear stresses of narrow beams, wide beams, and slabs are all very similar. 


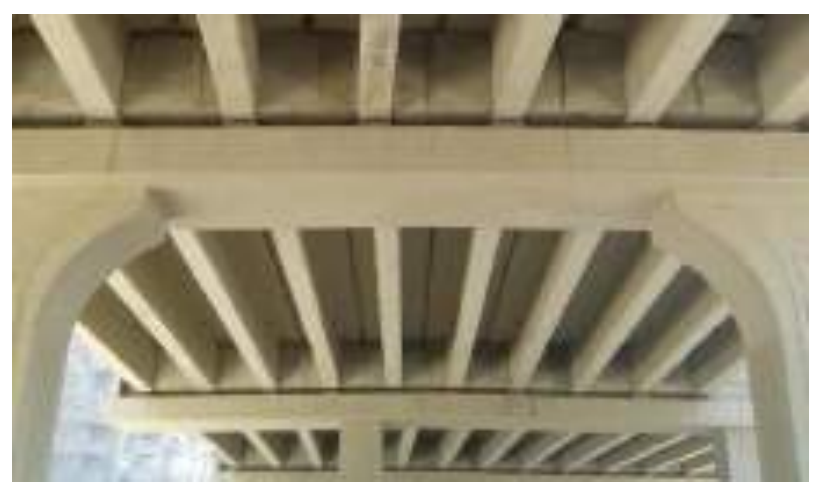

Figure 1: Wide shallow beams application in bridges

The influence of member width on the shear behavior was studied also by Antonio et al., 2015. The test series compared the capacities of wide specimens to narrow specimens having the same effective depth and longitudinal reinforcement ratio. Thus, Antonio concluded that member width was a significant parameter in predicting the shear stress at failure. S. E. Mohammadyan et al., 2014 investigated the shear capacity of six reinforced concrete wide beams with diverse types of reinforcement. The results revealed that using some numbers of independent bent-up bars significantly improved the shear capacity of wide beams. The combination of independent bentup bars with stirrups led to higher shear capacity and gradual failure of the specimen.

\section{RESEARCH SIGNIFICANCE}

The objective of this study is to determine the effect of the following parameters on the shear behaviour of wide shallow wide beams: (i) The effect of member width to depth ratio (b/d) and (ii) The effect of columns width to beam width ratio (c/b). On the other hand, the study addressed the adequacy of international codes requirements for shear design of wide shallow beams. A similar comparison is made between the experimental test results and analytical results obtained through the proposed model.

\section{EXPERIMENTAL PROGRAM}

\subsection{Specimen's description:}

Seven RC beams were tested under a four point loading system and a shear span-to-depth ratio (a/d) of 2.25 to achieve shear failure for all specimens. All beams had the same height $(250 \mathrm{~mm})$ and gross cover $(50 \mathrm{~mm})$, corresponding to an effective depth of $200 \mathrm{~mm}$. Moreover, all beams reinforced with the minimum amount of transverse shear reinforcement, was also produced: fourleg stirrups having a diameter of $8 \mathrm{~mm}$ at a longitudinal distance of $200 \mathrm{~mm}$. The longitudinal reinforcement was placed with a same reinforcement area; in particular, seven rebar's having a diameter of $22 \mathrm{~mm}$ were disposed in tension zone for all beams to prevent flexure failure and seven rebar's having a diameter of $12 \mathrm{~mm}$ were used in the compression zone to hold the stirrups in position. Also, for considering the effect of shear on bar force at support, 90o hooked anchorages were used at both ends, with a development length of $200 \mathrm{~mm}$. Table 1 summarizes all specimens geometry details. It should be noticed that, the column parts were reinforced properly with stirrups 
and axial reinforcement using appropriate anchorage length of bars in order to resist the applied load at failure.

\subsection{Materials properties}

All specimens were cast in plywood formwork simultaneously and cured under moist gunny. Seven standard cylindrical molds $150 \mathrm{~mm}$ in diameter and $300 \mathrm{~mm}$ high, one cylinder for each specimen, were cast at same time as the specimens and cured for control tests. Concrete samples were tested according to ASTM: C39/C39M-14, 2014 and the average compressive strength was 28.47 MPa .Steel bars of 8, 12, and $22 \mathrm{~mm}$ were used for stirrups, compression reinforcement, and tension reinforcement, respectively. The actual yield and ultimate stress for the used bars of different diameters evaluated according to ASTM A615 / A615M - 16, 2016. The yield strength for steel bars 8,12 , and $22 \mathrm{~mm}$ were 355,446, and 406 respectively.

Table1: Main characteristics of test specimens

\begin{tabular}{|c|c|c|c|c|c|c|c|c|}
\hline \multicolumn{9}{|c|}{ Group (I) } \\
\hline specimen & $\begin{array}{c}\mathrm{b} \\
\mathrm{mm}\end{array}$ & $\underset{\mathrm{m}}{\mathrm{d}}$ & $\begin{array}{c}\mathrm{c} \\
\mathrm{mm}\end{array}$ & $b / d$ & $\mathrm{c} / \mathrm{b}$ & $\begin{array}{c}\text { Tension } \\
\text { R.F.T }\end{array}$ & $\begin{array}{c}\text { Compression } \\
\text { R.F.T }\end{array}$ & $\begin{array}{l}\text { Shear } \\
\text { R.F.T }\end{array}$ \\
\hline B1 & 250 & 200 & 250 & 1.25 & 1.00 & $7 \varnothing 22$ & $7 \varnothing 12$ & Ø8@200mm \\
\hline B2 & 600 & 200 & 600 & 3.00 & 1.00 & $7 \varnothing 22$ & $7 \varnothing 12$ & Ø8@200mm \\
\hline B3 & 800 & 200 & 800 & 4.00 & 1.00 & $7 \varnothing 22$ & $7 \varnothing 12$ & Ø8@200mm \\
\hline B4 & 1000 & 200 & 1000 & 5.00 & 1.00 & $7 \varnothing 22$ & $7 \varnothing 12$ & Ø8@200mm \\
\hline B5 & 1400 & 200 & 1400 & 7.00 & 1.00 & $7 \varnothing 22$ & $7 \varnothing 12$ & Ø8@200mm \\
\hline \multicolumn{9}{|c|}{ Group (II) } \\
\hline specimen & $\mathrm{b}$ & $\mathrm{d}$ & $\mathrm{c}$ & $b / d$ & $\mathrm{c} / \mathrm{b}$ & Tension & Compression & Shear \\
\hline spectinteri & $\mathrm{mm}$ & $\mathrm{mm}$ & $\mathrm{mm}$ & ora & (10 & R.F.T & R.F.T & R.F.T \\
\hline B6 & 800 & 200 & 200 & 4.00 & 0.25 & $7 \varnothing 22$ & $7 \varnothing 12$ & Ø8@200mm \\
\hline B7 & 800 & 200 & 400 & 4.00 & 0.50 & $7 \varnothing 22$ & $7 \varnothing 12$ & Ø8@200mm \\
\hline B3 & 800 & 200 & 800 & 4.00 & 1.00 & $7 \varnothing 22$ & $7 \varnothing 12$ & Ø8@200mm \\
\hline
\end{tabular}

Where: $b=$ the width of beam section, $d=$ the effective depth of beam section, and $c=$ the width of column section, perpendicular length to centerline of beam.

\subsection{Testing setup and instrumentations}

All tested beams were loaded symmetrically with two equal concentrated loads, which resulted in a region of nearly constant moment over the central part of the beam. Instrumentations for all specimens were designed to capture the load-deformation behaviour, and determine variations in reinforcement strains, for the different beam widths and support configurations. A manual hydraulic jack with maximum capacity $1200 \mathrm{kN}$ loaded the beam by applying downward load by increment of $1.0 \mathrm{kN}$ up to failure and measured by the load cell attached to the jack. Vertical displacement measurements were recorded from LVDTs to capture differential deformations across the width of the members. Test setup for loaded specimens was depicted in Fig.2a.Shear strains were measured on the side faces of each specimen at mid line from face of column to the load point using one circular rosette of four side-mounted linear variable differential transformers (LVDTs) as shown in Fig.2.b. A system of LVDTs-based bulging gauges was used to measure the shear stress distribution cross the beam width by measuring the vertical increase of member thickness caused by diagonal cracking as shown in Fig.2.c. The holes through the concrete for the bulging gauge were formed with $6 \mathrm{~mm}$ diameter flexible plastic tubing that removed prior to the tests. The free movement of the LVDTs piston prevented the gauge from action as a force resisting element. For all beams, each stirrup in the shear span was instrumented with an electrical resistance strain gauge. 


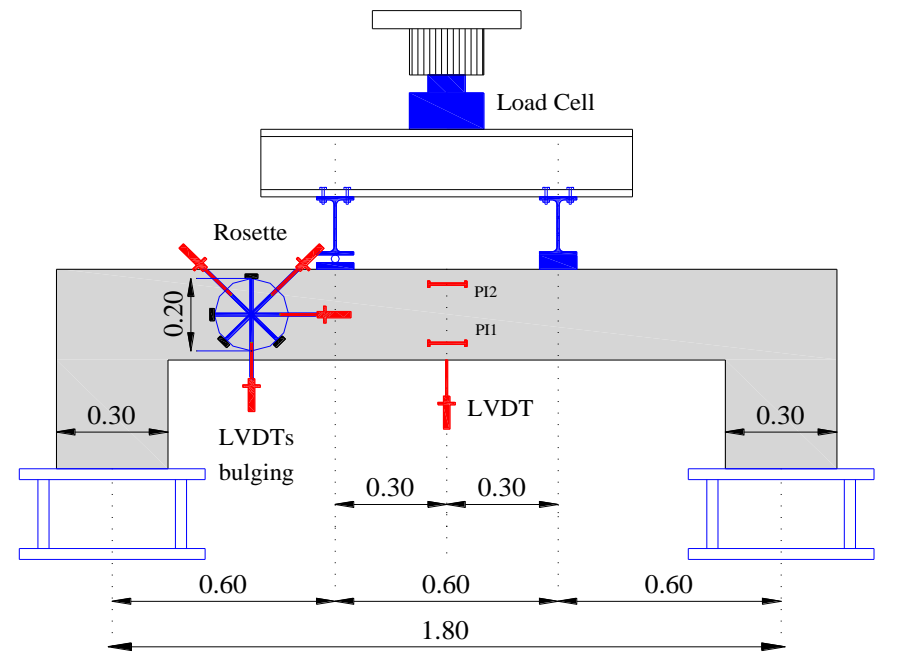

2.a) Sketch for dimension of test setup

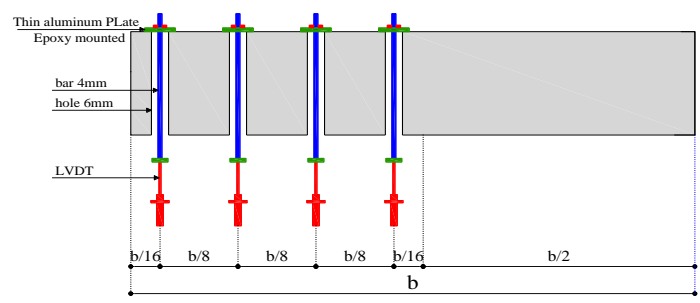

Beam cross section

2.b) The system of LVDTs-based bulging gauges

2.c) The system of LVDTs to obtain shear stress

Figure 2: Instrumentation and test set up

\section{EXPERIMENTAL RESULTS AND DISCUSSIONS}

\subsection{Crack patterns and failure modes}

In the early stages of loading, the beams were free of cracks. When a maximum tensile stress in the concrete was reached, vertical flexural cracks formed from the tension surface of the beam at intervals along the constant moment region. After the flexural cracks had extended upward a short distance above the longitudinal reinforcement, they extended further vertically in the pure moment zone. Shortly after the flexural crack formed, a small diagonal crack appeared suddenly slightly above the main steel level and at approximately the middle of the shear span. As the load increased, the inclined shear crack developed further towards the loading points and the supports. The rate of propagation of the inclined shear crack was different as b/d changed. Correspondingly the ultimate failure of the tested beams took different forms with a variation of width to depth ratio (b/d). The crack patterns for all specimens are shown in Fig.3.

For narrow beam (B1) with b/d ratio equals 1.25 , the inclined shear crack propagated very gradually toward the load point, and eventually crushing occurred somewhat above the crack in the reduced section. When the inclined shear crack reached a point somewhere above the neutral axis, several local diagonal cracks were formed at the level of the tension reinforcement, and gradually connected each other. For this beam the formation of the inclined shear crack did not 
cause failure; substantial additional load was resisted after the inclined shear crack initiated. The failure was sudden and loud, this failure mode is conventionally called shear compressive failure. For wide - shallow beams (B2), (B3), (B4), and (B5), it appears that the failure modes are directly related to the stability of the inclined shear cracks, which depends on b/d ratio. The inclined shear crack in beam B2 can be classified as an unstable crack because it propagated quickly without any additional load, resulting in separation of the member into two pieces. Whereas in beams B3, B4 and B5, an additional load was needed to extend the inclined shear crack, so that these cracks may be identified as stable cracks.

In group II, for all three specimens, flexural cracks near mid-span were detected first during initial load stages. Then, new flexural cracks formed in the shear spans and curved diagonally towards the loading point. The diagonal crack widths gradually increased as the applied load at mid-span increased. At the last stages of loading before failure $\left(\mathrm{P}>0.9 \mathrm{P}_{\max }\right)$, an existing diagonal crack rapidly widened and extended upwards to the loading plate. During the shear failure and after the occurrence of the crushing mechanism in the compressive concrete, cracking along the longitudinal reinforcement towards the support region was also observed in specimens. A significant difference in performance was related to the crack development on the side faces of the members. For specimens (B3) with where the support width extended to the specimen edge, the shear cracks terminated at the edge of the loading plate. However, when a narrow support was used, the shear crack extended horizontally past the centerline of the specimen. The difference in crack extent is explained by the lack of confining pressure in the latter case, which allows tensile splitting cracks to form. The results of all tested specimens are summarized in Table 2, which includes the load at the initiation of the flexural crack (flexural cracking load), at the initiation of the inclined shear crack (diagonal cracking load), and the failure (ultimate load). The flexural and diagonal cracking loads were determined from the direct observation of the crack patterns during the test. The stirrup strain measurements were also used to determine the diagonal cracking load as the load at which first significant increase of the stirrup strain crossing the inclined crack occurred.

Table 2: Specimen properties and test results

\begin{tabular}{cccccccccc}
\hline specimen & $\begin{array}{c}\mathrm{b} \\
\mathrm{mm}\end{array}$ & $\begin{array}{c}\mathrm{d} \\
\mathrm{mm}\end{array}$ & $\begin{array}{c}\mathrm{c} \\
\mathrm{mm}\end{array}$ & $\mathrm{b} / \mathrm{d}$ & $\mathrm{c} / \mathrm{b}$ & $\begin{array}{c}\text { Flexural } \\
\text { Cracking } \\
\text { Load (kN) }\end{array}$ & $\begin{array}{c}\text { Shear } \\
\text { Cracking } \\
\text { Load (kN) }\end{array}$ & $\begin{array}{c}\text { Ultimate } \\
\text { Load } \\
(\mathrm{kN})\end{array}$ & $\begin{array}{c}\text { Max. } \\
\text { Deflection } \\
(\mathrm{mm})\end{array}$ \\
\hline B1 & 250 & 200 & 250 & 1.25 & 1.00 & 35 & 171 & 397 & 11.62 \\
B2 & 600 & 200 & 600 & 3.00 & 1.00 & 73 & 407 & 735 & 12.20 \\
B3 & 800 & 200 & 800 & 4.00 & 1.00 & 95 & 540 & 809 & 9.45 \\
B4 & 1000 & 200 & 1000 & 5.00 & 1.00 & 116 & 648 & 884 & 7.71 \\
B5 & 1400 & 200 & 1400 & 7.00 & 1.00 & 160 & 869 & 1035 & 10.72 \\
\hline & & & & & & & & & \\
B6 & 800 & 200 & 200 & 4.00 & 0.25 & 75 & 528 & 655 & 17.99 \\
B7 & 800 & 200 & 400 & 4.00 & 0.50 & 80 & 537 & 736 & 13.73 \\
B3 & 800 & 200 & 800 & 4.00 & 1.00 & 95 & 540 & 809 & 9.45
\end{tabular}




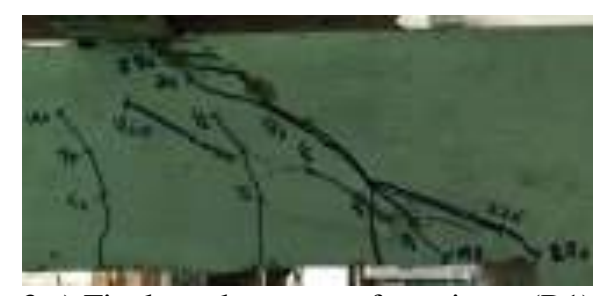

3.a) Final crack pattern of specimen (B1)

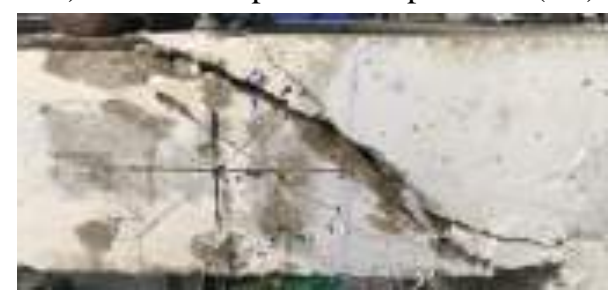

3.c) Final crack pattern of specimen (B3)

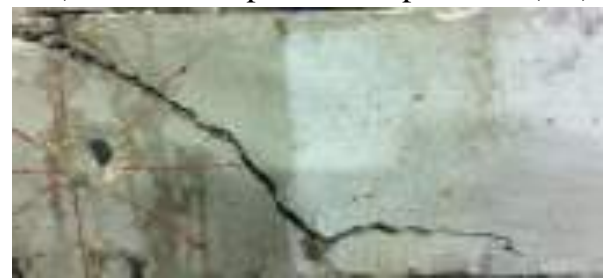

3.e) Final crack pattern of specimen (B5)

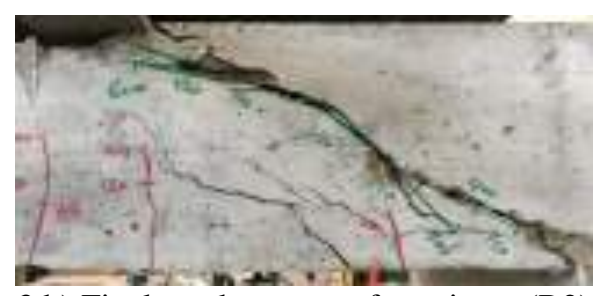

3.b) Final crack pattern of specimen (B2)

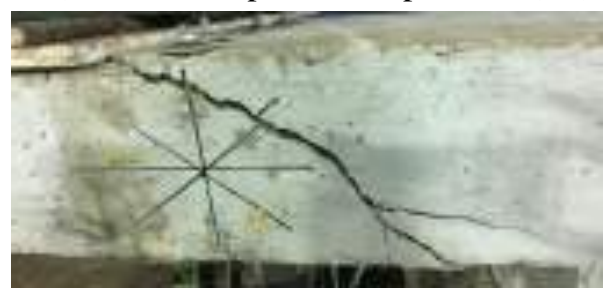

3.d) Final crack pattern of specimen (B4)

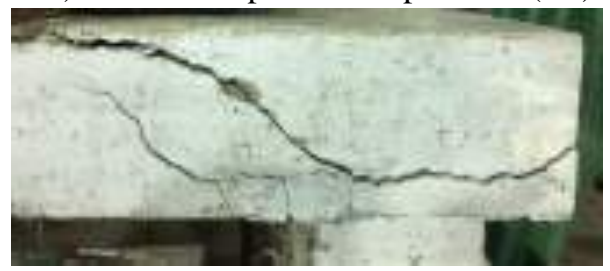

3.f) Final crack pattern of specimen (B6)

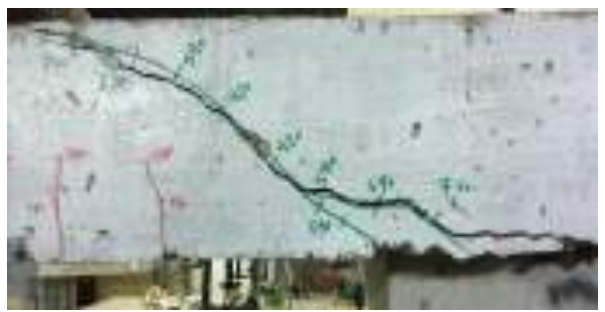

3.g) Final crack pattern of specimen (B7)

Figure 3: Final crack pattern of tested specimens

\subsection{Load-deflection relationships}

The load-deflection curves for the tested specimens of group I at mid-span are presented in Fig.4. As presented in this Figure, the general trend of the load-deflection curves was similar among the tested specimens of this group despite the change of the width to depth ratio (b/d). The loaddeflection curves of specimens may be roughly described by a bilinear relationship. The first stage starts from the beginning of loading to the point at which an inclined shear crack was first observed. In this stage, the beams acted linearly and the slopes (stiffness) were dependent on b/d ratio. The second stage starts from the point of the inclined shear crack initiation to the point of the ultimate load. Around the inclined shear cracking load, the stiffness generally started to decrease more rapidly. For narrow beam (B1) with b/d ratio equals 1.25 , the stiffness was little changed. However, for other specimens, the stiffness was considerably changed just after the inclined shear cracks were initiated. Noted that the vertical axis indicates the machine load over the ultimate maximum load to normalize the results for different widths. 
The load-deflection response of specimens of group II are shown in Fig.5. In contrast to the typical behaviour of RC members in flexure, the specimens in this group did not exhibit a sudden or large change of slope in the load-deflection plot at the initiation of flexural cracking. A non-linear relationship with gradually reducing slope was observed for specimens to shear failure. The loaddeflection response for specimen (B3) started to exhibit a plateau after reaching the ultimate load, mainly due to the non-linear behaviour of the longitudinal reinforcement. After some additional deformation in specimen, a significant diagonal crack formed leading to a shear failure, then a sudden and large drop in load was recorded at failure.

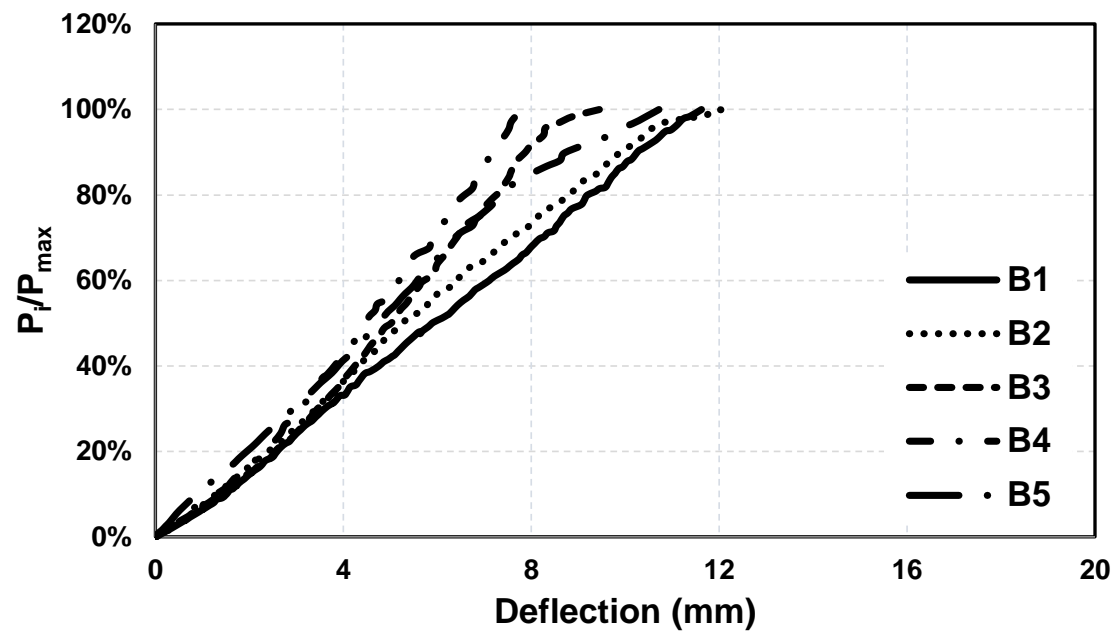

Figure 4: Experimental curves of the machine load vs. mid-span deflection for Group (I)

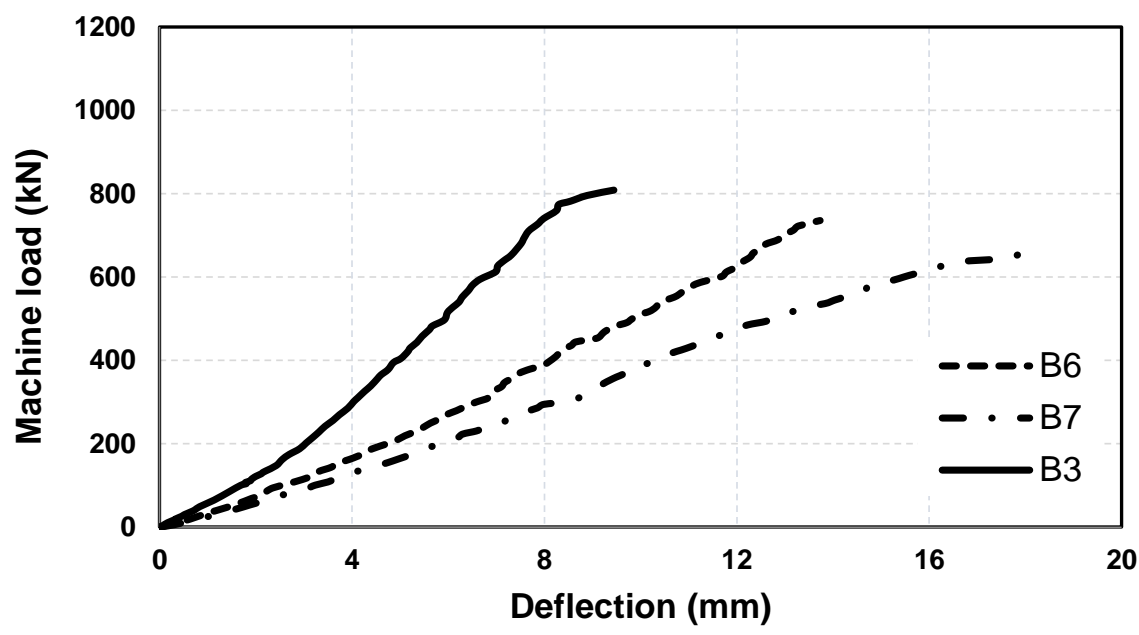

Figure 5: Experimental curves of the machine load vs. mid-span deflection for Group (II)

\subsection{Strains}

In all specimens, the trend of the shear stress-strain plots for strain gauges installed on the web reinforcement could be described by a tri-linear relationship. The first part of this relationship is defined by a line starting at the origin and extending along the vertical axis up to the appearance of the first inclined cracking. This behaviour indicates that, initially, the stirrups did not contribute to the shear strength of the beam until an inclined crack developed. However after inclined 
cracking, the second region of the shear stress-strain relationship started and extended up to the yielding strain of stirrups. At the beginning of this region, a small plateau related to the sudden opening of an inclined crack could be observed in some strain gauges. The third region in the shear stress-strain plots could be observed if the strain gauges installed on stirrups corresponds to a yielding plateau that extended up to failure of the specimen or the de-bonding of the gauge.

For curves relative to narrow beam (B1), it appears that the tensile strain in inner stirrups the same tensile strain in outer stirrups and equal to the 800 micro strain, it is clear that the shear stress distribution on the width of the cross section is constant. However, for another wide-shallow beams the average tensile strain in inner stirrups is 33\% the average tensile strain in outer stirrups so that indicates that the shear strain distribution on the width of the section is variable as shown in Fig.6. For specimen (B6) with support width equal to $25 \%$ of the beam width, the inner stirrups tensile strain reached to yield strain (1209 micro strain), however the tensile strain of the outer stirrups is 460 micro strain, $38 \%$ of yield strain. On the other hand, the behaviour of strains for specimen (B3), full width supporting, is in the opposite way, the inner stirrups tensile strain reached to 417 micro strain (35\% of yield strain), however the tensile strain of the outer stirrups reached to yield strain as shown in Fig.7.

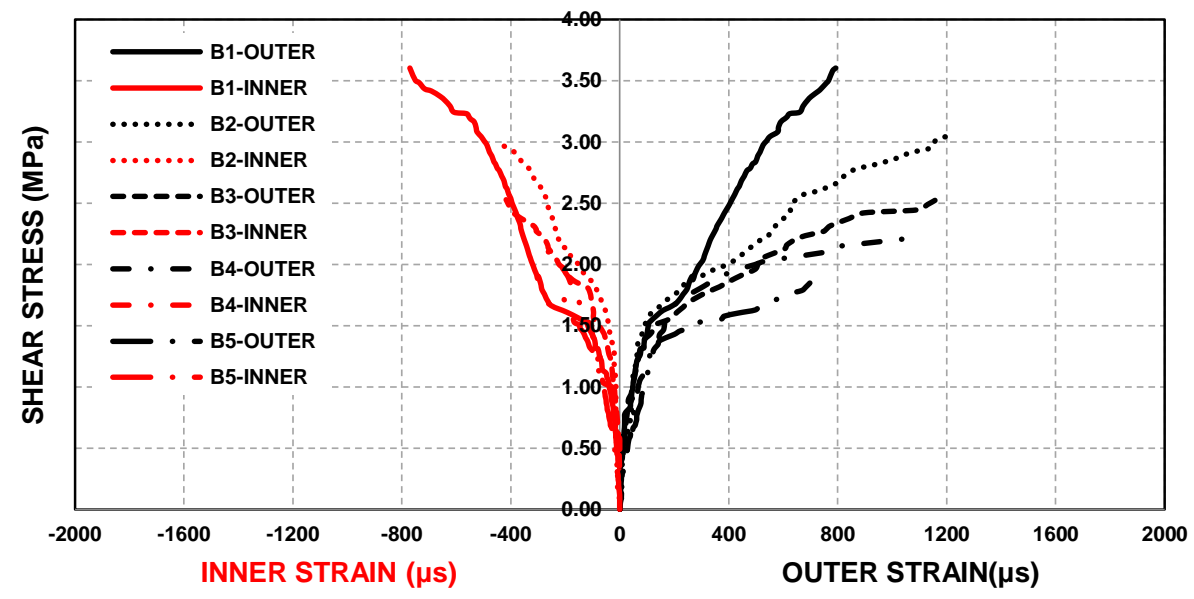

Figure 6: Shear stress vs. shear strain in outer and inner stirrups for Group (I)

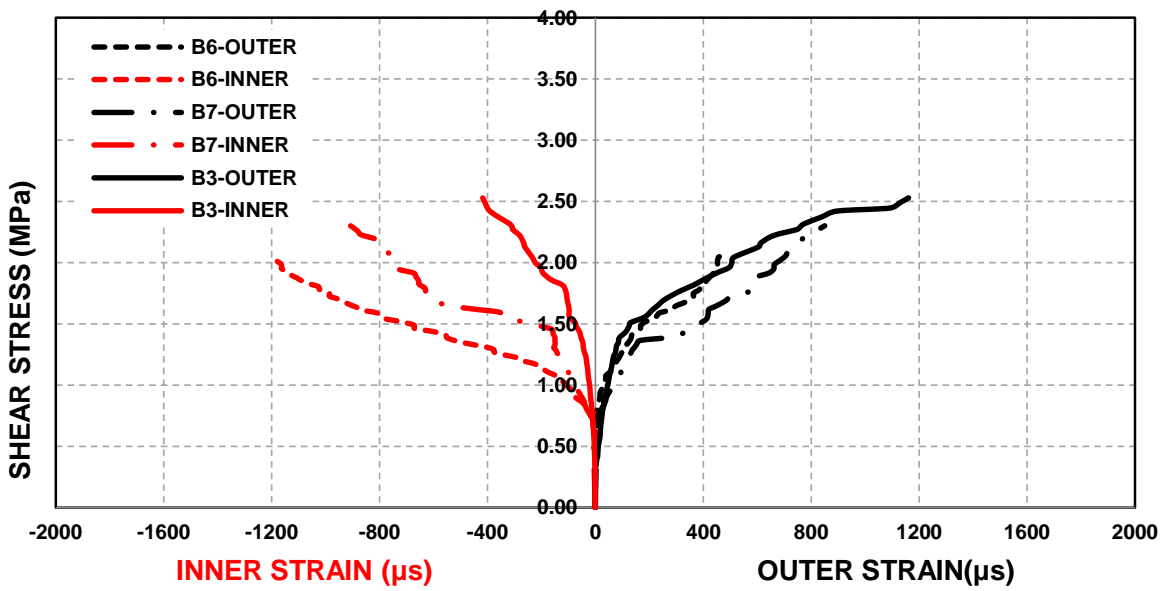

Figure 7: Shear stress vs. shear strain in outer and inner stirrups for Group (II) 


\subsection{Strain distribution on width of cross section}

Fig. 8 shows the strain distribution on width of cross section that was measured using a system of LVDTs-based bulging gauges by measuring the vertical increase of member thickness caused by diagonal cracking. By analyzing the curve of narrow beam (B1), the shear stress is approximately constant over the cross section. However, the shear stresses for wide shallow beams have the minimum values at mid-point and the maximum values of the outer face. For wide-shallow beams (B2-,B3, B4 and B5), the shear stress at mid-point decrease by an average 27\% compared with the value at the outer face and this conclusion lead to that the width of the cross section is very important parameter in design implication for shear. However, the changing of the column width to beam width (c/b) from $25 \%$ to $100 \%$ has a strong effect on the shear behaviour of reinforced concrete wide-shallow beams. Fig.9 shows a prominent influence on the shear strain distribution. The shear strain trend of narrow column is contrasting to the trend of wide column, the maximum strain at mid-width for narrow column but the maximum strain at face of the width for wide columns.

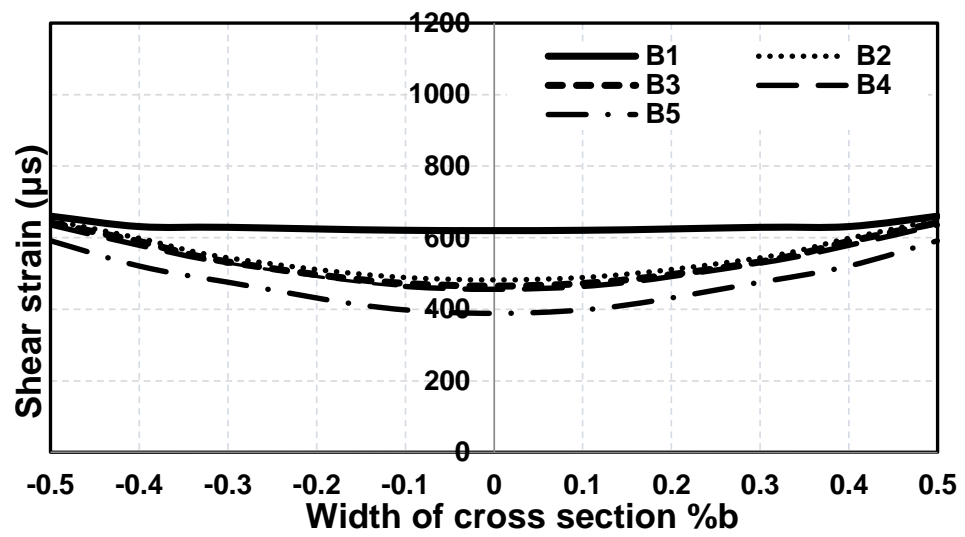

Figure 8: Shear strain distribution on cross width for specimens in Group (I)

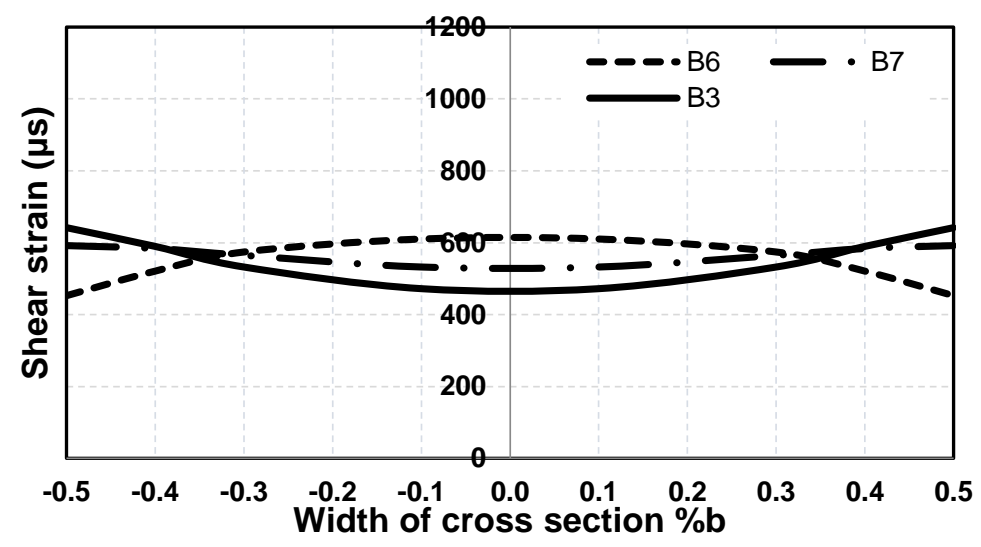

Figure 9: Shear strain distribution on cross width for specimens in Group (II)

\section{COMPARISONS WITH INTERNATIONAL CODES}

Table 3 shows a number of predictive equations for the shear design formulas for beams in different design codes. Fig. 10 reports the comparison between the experimental shear crack load and the shear strength predicted by shear design formulas. It can be observed that ACI318-08, 
AASHTO LRFD-2005, and EC2-04 codes are un-conservative, however the estimations that obtained by using CSA-A23.3-04 is conservative. This conclusion confirms the fact that the contribution of concrete formals of the international codes must be recalibrated. 
Table 3 Predictive equations for shear strength of RC beams

\begin{tabular}{lc}
\hline \multicolumn{1}{c}{ Reference } & Predictive equation \\
\hline ACI 318-08,2008 & $V_{c}=0.17 \sqrt{f^{\prime}{ }_{c}} b d$ \\
AASHTO LRFD,2005 & $V_{c}=0.083 \beta \sqrt{f^{\prime}} b d$ \\
EC2,2004 & $V_{R d, c}=\left[C_{R d, c} k\left(100 \rho f_{c k}\right)^{1 / 3}\right] b d$ \\
CSA A23.3-04,2004 & $V_{c}=\phi_{c} \lambda \beta \sqrt{f_{c}^{\prime}} b d$ \\
\hline
\end{tabular}

\section{Where}

$\mathrm{V}_{\mathrm{c}}, \mathrm{V}_{\mathrm{Rd}, \mathrm{c}} \quad$ The nominal shear strength provided by concrete.

$\mathrm{f}_{\mathrm{c}}{ }^{\prime} \quad$ The concrete compressive cylinder strength (MPa).

$\mathrm{f}_{\mathrm{ck}} \quad$ The characteristic concrete cube strength (MPa).

b The web width of section (mm).

The distance from the extreme compression fiber to the central axis of the longitudinal

d reinforcement $(\mathrm{mm})$.

$\beta \quad$ The factor indicating the ability of diagonally cracked concrete to transmit tension.

$\lambda \quad$ The strength reduction factor.

$\emptyset_{c} \quad$ The resistance factor for concrete.

$\rho \quad$ The tensile reinforcement ratio.

$\gamma_{c}$ The concrete partial safety factor.

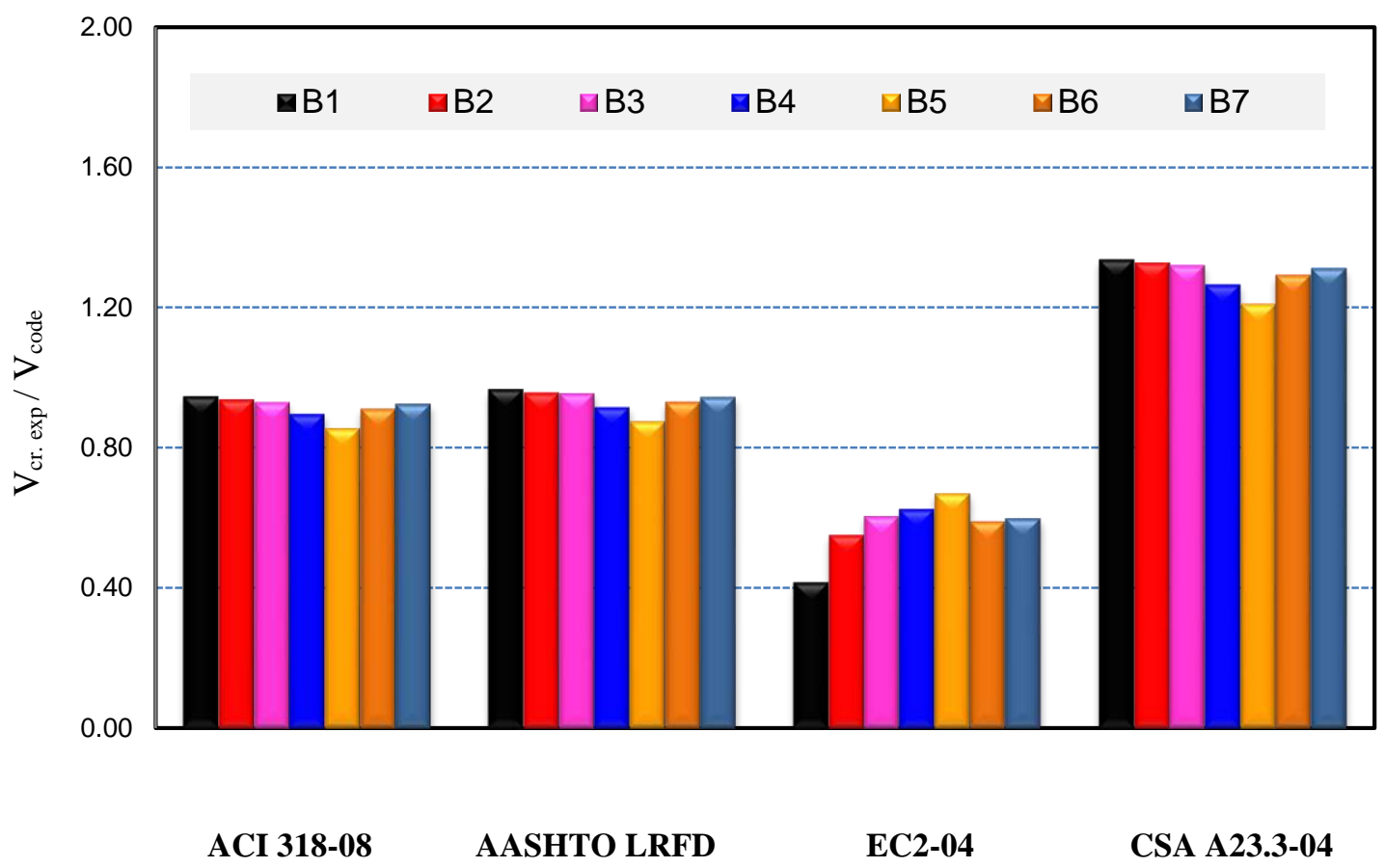

Fig. 10 Expermental vs. Predicted shear force 


\section{CONCLUSIONS}

The behaviour of reinforced concrete wide-shallow beams under shear loading has been analyzed in this manuscript, focusing on the influence of width-to-effective depth ratio and support width to beam width. Based on the experimental test results obtained in this study, the following conclusions can be drawn:

1. The ratio between width-to-effective depth ratios (b/d) in wide-shallow beams seems to significantly influence the mechanism of failure and the shear capacity.

2. Wide-shallow beams that were supported over a portion of their width had a decrease in shear capacity over members with full width conditions. Capacity prediction models must account for this influence, to accurately estimate the failure strength of wide members.

3. For a wide- shallow beams, simply-supported member supported on columns with partial width, the distribution of strains in the concrete varies across the member width. Furthermore, this distribution changes from that of typically higher strains in the outer point to higher strains in the middle point near the supports.

4. Most of current analytical formulations for shear disregarded the losses in shear resistance due to different values of width-to-effective depth ratio (b/d) and support width to beam width ratio $(\mathrm{c} / \mathrm{b})$.

\section{REFERENCES}

ACI Committee 318, "Building Code Requirements for Structural Concrete (ACI 318-08) and Commentary," American Concrete Institute, Farmington Hills, MI, 2008, 473 pp.

Antonio Conforti, Fausto Minelli, Andrea Tinini, Giovanni A. Plizzari, "Influence of polypropylene fibre reinforcement and width-to-effective depth ratio in wide-shallow beams', Engineering Structures 88(2015)12-21.

ASTM A615/A615M-16: Standard Specification for Deformed and Plain Carbon-Steel Bars for Concrete Reinforcement, 2016.

ASTM Standers: C39-C39M-14, ASTM committee C09 on concrete and concrete aggregates, 2014.

Bentz, E. C. (2005). "Empirical modeling of reinforced concrete shear strength size effect for members without stirrups.” ACI Struct. J., 102(2), 232-241.

CSA Committee A23.3: Design of concrete structures, CSA A23.3-04, Rexdale, Ontario, Canada: Canadian Standards Association, 2004.

Euro code 2, "Design of Concrete Structures-Part 1-1: General Rules and Rules for Buildings (EN1992-1-1)," European Committee for Standardization, Brussels, Belgium, Dec. 2004, 451 pp.

L.R.F.D. AASHTO, Bridge Design Specifications and Commentary, third ed., American Association of State and Highway Transportation Officials, Washington, DC, 2005. 
Lubell, A. S.; Bentz, E. C.; and Collins, M. P., "Shear Reinforcement Spacing in Wide Members," ACI Structural Journal, V. 106, No. 2, Mar.-Apr. 2009, pp. 205-214.

S. E. Mohammadyan-Yasouj, A. K. Marsono, R. Abdullah, and M. Moghadasi, 2014, "Wide Beam Shear Behavior with Diverse Types of Reinforcement," ACI Structural Journal, V. 111, No. 1-6, Dec.-Jan. 2014.

Serna-Ros, P.; Fernandez-Prada, M. A.; Miguel-Sosa, P.; and Debb, O. A. R., "Influence of Stirrup Distribution and Support Width on the Shear Strength of Reinforced Concrete Wide Beams," Magazine of Concrete Research, V. 54, No. 3, 2002, pp. 181-191. doi: 10.1680/macr.2002.54.3.181.

Sherwood, E. G.; Bentz, E. C.; and Collins, M. P., "Effect of Aggregate Size on Beam-Shear Strength of Thick Slabs,” ACI Structural Journal, V. 104, No. 2, Mar.-Apr. 2007, pp. 180-190. 